This is a pre-copyedited, and pre-reviewed author-produced PDF of an article accepted for publication in the JOURNAL OF SECOND LANGUAGE WRITING. There is a twoyear embargo before a reviewed version of the article can be published on an author website.

Jim McKinley, University College London

Heath Rose, University of Oxford

\title{
Conceptualizations of language errors, standards, norms and nativeness in English for research publication purposes: An analysis of journal submission guidelines
}

Adherence to standards in English for research publication purposes (ERPP) can be a substantial barrier for second language (L2) writers and is an area of renewed debate in L2 writing research. This study presents a qualitative text analysis of author guidelines in 210 leading academic journals across 27 disciplines. It explores conceptualizations of language errors, standards, norms and nativeness in journal submission guidelines, and identifies key concepts related to so-called error-free writing. Findings indicate that most of the journal guidelines are inflexible in their acceptance of variant uses of English. Some guidelines state a requirement of meeting an unclear standard of good English, sometimes described as American or British English. Many guidelines specifically position L2 writers as deficient of native standards, which raises ethical considerations of access to publication in top journals. This study leads to a discussion of a need to reconceptualize error-free writing in ERPP, and to decouple it from concepts such as nativeness. It focuses on a need to relax some author guidelines to encourage all authors to write using an English that can easily be understood by a broad, heterogeneous, global, and multilingual audience.

Highlights:

- A systematic analysis of language guidelines of 210 leading journals across 27 disciplines

- Implicit evidence of bias to native writing norms is highlighted

- A reconceptualization of error in English academic writing is proposed

Keywords: standard English; error-free; English as a Lingua Franca; English for research publication purposes; journal submission guidelines

\section{Introduction}

English for research publication purposes (ERPP) is a term describing the language used within the highly constrained domain of written research output (Cargill \& Burgess, 2008). As English has developed into a global academic lingua franca, academics are experiencing rising pressure "to increase international publication, where ENL [English as a Native Language] writing standards seem to be the only accepted norm" (Ingvarsdóttir \& Arnbjörnsdóttir, 2013, p. 123). Conventions in academic writing are 
highly standardized and safeguarded by publishers, who are often resistant to change due to a long history of standardization and uniformity in commercial publishing (Galloway \& Rose, 2015).

With the increase of English L2 users comes an increase of English L2 writers, readers, teachers, reviewers, and editors, who struggle to work within standards of academic English, without a clear understanding of what the standards are. While good academic English is often described as error-free, the lack of a clear understanding of the standards of academic English poses dilemmas for all participants in academic English writing processes, especially English L2 scholars. Thus, there is a need now more than ever for an investigation of topics such as error, standards, norms and nativeness in policy documents related to ERPP, which may be used and interpreted differently by gatekeepers (e.g. editors and reviewers) and prevent English L2 scholars from getting their work published.

It may be useful to use the guidelines of the Journal of Second Language Writing as an example. Published by Elsevier, the journal carries with it one of Elsevier's standard language guidelines promoting its editing service, specifically:

Please write your text in good English (American or British usage is accepted, but not a mixture of these). Authors who feel their English language manuscript may require editing to eliminate possible grammatical or spelling errors and to conform to correct scientific English may wish to use the English Language Editing service available from Elsevier's WebShop. ${ }^{1}$

We found this guideline rather striking for several reasons. First, the use of the subjective concept of good English carries with it an implied stipulation serving as a kind of definition: that good English is either American or British English, and that this is the language described as conforming to correct scientific English. It suggests a standard is correct, but is unclear of what scientific English is, apart from being free from grammatical or spelling errors. Although the guideline does not explicitly conflate poor writing with concepts of nativeness, it does make a link between good writing with concepts of correctness and adherence to British and American standards. We imagined guidelines like this must be daunting for many English L2 authors. We also wondered whether the exponential increase of English L2 authors had been accompanied with a loosening of attitudes toward English for research publication purposes in terms of publishers becoming more open in their acceptance of variation in the language. Thus, we decided to explore this phenomenon more widely to see whether the Journal of Second Language Writing's policy was reflective of journal submission guidelines across disciplines and publishers. Specifically, this study was designed to investigate the relationship between error and L2 academic writing expectations, first by reviewing related literature at the nexus of error and L2 academic writing, including mounting calls for more inclusivity in ERPP. The paper draws on both

\footnotetext{
${ }^{1}$ https://www.elsevier.com/journals/journal-of-second-language-writing/1060-3743/guide-forauthors
} 
L2 writing research as well as work from critical applied linguistics to challenge current publishing practices in upholding so-called error-free writing standards. To investigate guidelines in ERPP more widely, this paper presents data from a systematic analysis of academic journals' language submission guidelines for the top 10 impact factor journals in all 27 subject areas in the Scimago Journal Index, which uses SCOPUS as its data source. Through qualitative text analysis of guides to authors, we analyzed explicit mentions of error and grammatical accuracy, as well as statements related to the nativeness of authors, including recommendations for proofreading by native speakers of English. The findings of the study are then discussed in the wider context of applied linguistics, to explore future directions to challenge conceptualizations of error in ERPP.

\section{Standards in English for Research and Publication}

With the growth of English as an academic lingua franca, there has been an increase in L2 English scholars publishing their research in English. According to Galloway and Rose (2015), "English holds a near monopoly of published research" which is "a situation unlikely to change in the future" (p. 234). Mauranen (2016) remarks "it is of course undeniable that English as an academic language plays a central role in all domains where international concerns are at stake" (p. 31), including publications. She draws on Gentil and Séror (2014), who state that "the quasi-hegemony of English in scientific publications is now a fait accompli" (p. 18). In non-English speaking universities, notions of being a "good researcher" are increasingly connected with proficiency in English (Olsson \& Sheridan, 2012). It is estimated that there are 5.5 million scholars working in over 17500 research and higher education institutions worldwide (Lillis \& Curry, 2010, p. 1), indicating that issues surrounding ERPP potentially affect a large number of people worldwide.

The role of English within research and publication practices has been linked to neoliberal pushes for universities to Englishize in order to internationalize (Rose \& McKinley, 2018). This has resulted in an increase in scholars publishing in English as a second language. In China, for example, recent years have seen huge pushes for researchers to publish in English to increase university reputations as world-class universities (Huang, 2015). Montgomery (2013) predicts that "given recent trends, the Chinese could even match the US levels in peer-reviewed English-language 'output' by about 2025, perhaps sooner" (p. 84).

Despite the growth in research output from English L2 writers, numerous scholars have highlighted the disadvantages that L2 English academics experience in publishing (e.g. Jenkins, 2011; Lillis \& Curry, 2010; Mauranen, 2016). In doing so, they draw on the debate about the concept of nativeness pertaining to standards in ERPP. Jenkins (2011) argues that international journals have an international, rather than a native audience, and thus guidelines that promote adherence to native standards are unjustified and serve to disadvantage academics based on language alone. Seidlhofer (2011) observes an inequality between non-native and native English speakers in terms of the perceived acceptableness of the English they use: 
Non-native speakers just cannot win: either they subject themselves to nativespeaker authority and obediently strive to meet the norms of the hegemonic language, or they try to assert themselves against the hegemony, only to then be told that they got it wrong. (p. 34)

A number of recent studies of the experiences of L2 English writers have further highlighted a perceived disadvantage for L2 writers when writing for publication purposes (e.g. Duszak \& Lewkowicz, 2008; Ferguson, Perez-Llantada, \& Plo, 2011; Hanauer \& Englander, 2011; Hwang, 2005; Lillis \& Curry, 2010).

Ken Hyland (2016) challenges these disadvantages in his article titled "Academic publishing and the myth of linguistic injustice". He argues that there is little evidence of linguistic disadvantages of English L2 authors, and that a focus on such disadvantages can have negative consequences for academic publishing in general. However, as Politzer-Ahles et al. (2016) point out, the disadvantages cannot be disregarded as myth, as this would ignore the linguistic privilege afforded to English L1 authors. This privilege is implied in some language guidelines of leading journals across the disciplines that conflate an ability to produce error-free writing with nativeness, by suggesting that L2 writers have their manuscripts checked by a native speaker.

In a special issue of the Journal of English for Academic Purposes on writing for publication in multilingual contexts, Gentil and Séror (2014) address the linguistic disadvantages of English L2 authors and contextualize them geopolitically, pointing to the challenges of balancing English with other languages. Interestingly, not one of the articles in that issue explores the concern of language error. Only Li (2014, p. 48) includes a single mention of the word mistake in an excerpt from a Chinese academic, who described using dictionaries and Google to avoid making mistakes. But there is no further analysis of this point, and no discussion of error in ERPP. In another article in the same special issue, McGrath (2014) operationalizes the word variation in reference to language variation, and also mentions "micro- and macro-level features of Englishlanguage academic discourse" (p. 13) for analyzing her data. But there is no reference of the relation of these aspects to error.

The establishment of error-free writing as the goal of teaching academic writing is widespread. A typical example can be found in Weisman and Zornado's (2017) book Professional Writing for Social Work Practice (2 ${ }^{\text {nd }}$ edition). In the preface ("To the reader"), they emphasize the importance of writing "so that it makes sense", using "appropriate language" to produce "(gulp) error-free writing" (p. xi). Toward the end of the preface, they clarify that getting the writing "right" matters-that is, it needs to follow "standard conventions of written English" ( $p$. xvii). On the idea of academic English style, Wallwork's (2016) book titled Academic Written English: What it is and how to teach it explicitly addresses mistakes made by L2 writers. He suggests that non-native writers are more likely to commit mistakes when using long-winded phrases:

It opens up a minefield of mistakes - the more complicated the grammatical structures the longer the sentences and typically the more mistakes a non-native 
author will make (native authors at least don't normally have the problem of being grammatically correct or using the right words). (Wallwork, 2016, p. 70)

Wallwork's focus on mistakes, and the non-native author's likeliness to falter to them unlike the native author, seems particularly egregious. It nevertheless further highlights a conflation of error-free writing with a writer's nativeness.

\section{Alternative perspectives of error in academic writing}

Calls to redefining error were made nearly four decades ago by scholars in English writing such as Shaughnessy (1977), and later, supported by Harris (1981). In Hartwell's (1985) analysis of the teaching of grammar, he draws from these calls to make his own emphatic plea, that "we need to attempt some massive dislocation of our traditional thinking, to shuck off our hyperliterate perception of the value of formal rules" (p.121). At the 2015 Symposium on Second Language Writing in Auckland, New Zealand, in light of influences from globalization, Ryuko Kubota (2015) made the familiar call for a need to redefine error. While this is not a new proposal, it has recently gained traction due to large theoretical shifts currently occurring as part of the 'multilingual turn' in second language acquisition (see May, 2014; Ortega, 2013).

In an earlier publication in the Journal of Second Language Writing, Heng Hartse and Kubota (2014) argue that the acceptance of deviations from standard written English has been long advocated in L2 writing research. However, they state that the process via which pluralization can be achieved remains underexplored and "becomes contentious in high-stakes academic writing, which entails negotiation between L2 writers and gatekeepers (such as editors and copyeditors) who are expected to ensure academic sophistication and rigor of published texts" (Heng Hartse \& Kubota, 2014, p. 71). They discuss three influential alternatives to error-based approaches to $L 2$ writing:

The world Englishes approaches, which advocate accepting multiple varieties of English. Translingual approaches, which view texts as hybrid constructions influenced by multiple linguistic and rhetorical factors. The Written English as a lingua franca approaches, which investigate written language usage in terms of features common to nonnative English speakers' discourse. (Heng Hartse \& Kubota, 2014, p. 73)

The authors then apply these alternative approaches to the context of academic publishing and conclude that changing practices in academic publishing present ongoing challenges due to persistent ideologies surrounding language standards.

Critical applied linguists have also problematized traditional views of error, as it is a construct that is as fluid and changeable as language. Canagarajah (2015) makes a point to differentiate between error and mistake, stating that error is systematic and indicates "a personal 'grammar' of the writer" (p. 427). This is what Byrnes, Maxim and Norris (2010, p. 159) refer to as "patterned errors". Canagarajah also refers to error in two different collocations: error correction and error treatment. Correction, he explains, 
in light of recent translingual practices, is in need of reconsideration. Treatment is used when he refers to discussions of error in L2 writing research.

Challenges to traditional standards of English (i.e. a difference perspective versus a deficit perspective) have also been well established in English as a lingua franca (ELF) and World Englishes literature (e.g. Jenkins, 2000, 2006, 2009; Mauranen, 2012, 2016). Jenkins (2006) states that "certain forms that are habitually labelled 'errors' in EFL may be variants in ELF" (p. 141). And while she admits much of the focus in modern foreign language education, including EFL, remains on a deficit perspective, she offers an important alternative: "From a World Englishes perspective, deviations from [native speaker] norms thus become linguistically interesting (but otherwise neutral) 'differences' rather than 'deficits'” (Jenkins, 2006, p. 140).

While scholars such as Jenkins and Mauranen are finding ways to neutralize the inherent belittling of L2 uses of English, they do this by relying on the use of the native/non-native distinction as a way of explaining the characteristics of academic writing. This distinction seems to be somewhat paradoxical by maintaining an us and them situation, and by inadvertently conflating error with nativeness. However, the native/non-native distinction is the one that scholars continue to use to identify differences in English language usage (e.g. Gamon, 2010; Han, Chodorow, \& Leacock, 2006). In a stylometric analysis of scientific research papers (Bergsma, Post, \& Yarowsky, 2012), results showed that error analysis could identify, with $94.6 \%$ accuracy, non-native authors by features of style and syntax.

Martinez (2018) conducted a study comparing a corpus of 192 non-native authored articles in eight food-science international journals with a similar corpus of nativeauthored articles from the same journals. His sample spanned two different time periods (2000-2005 and 2010-2015). He found some word choices and phrasing were used only by writers from certain non-English language backgrounds. His study further revealed certain lexical items and word choices were present in the non-native corpus, which were considered non-standard in the native corpus, such as the noun form of researches as plural for research. The comparison between the two periods further revealed that all items had become increasingly acceptable over the years. He contends that ELF-like uses of English appearing in international scholarly publications, such as Spanish L1 authors' use of specially instead of the normative especially, and besides used as a synonym for furthermore by Chinese L1 authors, can serve to alleviate concerns of English L2 writing scholars.

In summing up the literature, previous research has suggested potential languagebased discrimination for L2 writers when engaging in ERPP (e.g. Jenkins, 2011), which is a position both supported (e.g. Hanauer \& Englander, 2011; Lillis \& Curry, 2010) and rejected (e.g. Hyland, 2016) by scholars. Some literature suggests that deviations from standards which are associated with non-native writing are viewed as wrong (Seidlhofer, 2011), while other literature suggests that publishers are becoming more accepting of ELF forms, which may previously have been seen as deviant (Martinez, 2018). To evaluate both claims, what is needed is a thorough and systematic analysis of 
actual journal guidelines to establish publisher perspectives of error and L2 writing in ERPP. The study which follows aims to fill this gap.

\section{The study}

The study aimed to explore the language-related requirements in author guidelines of academic journals in order to evaluate their positions on error, standards, norms, and L2 writing. Our two main research questions were:

1. How are conceptions of language errors, standards, norms, and nativeness reflected in journal language guidelines for authors?

2. How does the wording of author guidelines portray flexibility or rigidity towards diverse forms of language in ERPP?

In answering these questions, we sought to explore the positioning of second language writers of ERPP within author guidelines, by exploring the extent to which journals asserted traditional standards over pluralistic views that have been advocated in L2 writing literature. In answering these research questions, we were also interested in discovering the relationship between conceptions of error with second language writing to establish whether a linguistic disadvantage exists at journal policy level.

As the study aimed to explore practices of gatekeepers, top journals across all disciplines of academic writing were sampled. The journals were chosen based on the Scimago Journal Index. To ensure a multi-disciplinary sample, the top 10 impact-factor journals in all 27 of the indexed research areas were identified, resulting in a total sample of 270 . In the sample, 60 journal titles were repeated, due to being listed under multiple disciplines. To avoid duplication, these were only counted once in the sample, resulting in a total of 210 different research journal guidelines.

Each journal's guide for authors was analyzed for concepts related to errors, standards, norms, and nativeness of the author. Analysis was done in an interpretive, qualitative tradition as opposed to a corpus-like search, as an initial review of the guidelines revealed subtle nuances and differences in terms of how these concepts like errors, standards and norms were discussed. This subtlety required an interpretive, rather than positivist, approach to the analysis, which was better achieved via qualitative text analysis, sometimes referred to as qualitative content analysis, or thematic qualitative text analysis (Kuckartz, 2014). As Heng Hartse and Kubota (2014) note, "guidelines are frequently vague" (p. 76); thus, our analysis of them required a flexible and adaptive approach which embraced researcher interpretation.

The journals were categorized according to their guidelines' interpreted openness to variation in standards of language use, including openness to submissions from L2 writers. Each journal guideline was identified as flexible (i.e. explicitly states some degree of flexibility in language, or explicitly encourages contributions from L2 writers without concern over use of English), rigid (i.e. explicitly states a need to adhere to native-like standards, or requiring 'native checks' for L2 writers), both (i.e. the guidelines 
include both flexible and rigid descriptors), neutral (i.e. it mentions language use but does not explicitly state any judgement regarding standards, or native norms), or not mentioned (there is no mention of language in the submission guidelines).

Using this framework, we then categorized the 210 journals' language guidelines, systematically keeping track of the key phrases used to place the journal within a category, so that the interpretations could be checked. The categorization process was carried out by a research assistant and one of the researchers with expertise in L2 writing. They then checked the results and negotiated any disagreements with each other to confirm a single categorization for each journal. The categorizations were then checked by the second researcher with expertise in the area of English as an international language, which was particularly useful to make judgements over any interpreted bias according to nativeness or language norms. The two researchers then discussed the difficult cases and finalized the results. Table 1 provides some examples of statements which facilitated each type of categorization. While we have aimed to increase transparency through thick methodological descriptions, and to increase reliability through use of multiple researchers, we acknowledge that other researchers may have produced different interpretations based on the same data.

Table 1: Examples of categories

\begin{tabular}{|l|l|l|}
\hline Category & Journal & Example excerpt \\
\hline Flexible & $\begin{array}{l}\text { Nature } \\
\text { Nanotechnology }\end{array}$ & $\begin{array}{l}\text { Nature Nanotechnology is read by scientists } \\
\text { from diverse backgrounds. In addition, many are } \\
\text { not native English speakers. Authors should, } \\
\text { therefore, give careful thought to how their } \\
\text { findings may be communicated clearly. No } \\
\text { paper will be rejected for poor language. }\end{array}$ \\
\hline Rigid & $\begin{array}{l}\text { Clinical } \\
\text { Microbiology } \\
\text { Reviews }\end{array}$ & $\begin{array}{l}\text { Manuscripts may be editorially rejected, without } \\
\text { review, on the basis of poor English or lack of } \\
\text { conformity to the standards. }\end{array}$ \\
\hline Bath & Medicine & $\begin{array}{l}\text { No paper will be rejected for poor language. } \\
\text { However, if you would like assistance with } \\
\text { writing your manuscript, you can consider } \\
\text { asking a colleague whose native language is } \\
\text { English. }\end{array}$ \\
\hline Neutral & $\begin{array}{l}\text { Annual Review } \\
\text { of Ecology, } \\
\text { Evolution, and } \\
\text { Systematics }\end{array}$ & $\begin{array}{l}\text { Please proofread carefully for both errors and } \\
\text { inconsistencies. }\end{array}$ \\
\hline
\end{tabular}

We then analyzed key terms by exploring statistical differences in the lexical items within the rigid and flexible guidelines. This method was used by Martinez (2018), in which he compared published journal articles written by L1 English speakers with those written by L2 English speakers to create lists of words to review for those that 'stood out' as meaningfully different. Martinez (2018, p. 43) explains, "here 'stood out' is 
essentially operationalized as a content word (i.e. not a grammatical or function word, such as an article or particle)".

Using corpus analysis software AntConc (Anthony, 2018), we compared languagerelated coded excerpts from the flexible guidelines with a reference text comprised of excerpts from the rigid and neutral guidelines. Words that appeared three times or more and had a keyness (log likelihood) above $6.63(\mathrm{p}<.01)$ were then explored further within the software to investigate differences in use. We then followed the same process to compare the excerpts from rigid guidelines with a reference text created from the flexible and neutral guidelines to explore the lexical items associated with a rigid stance towards language standards. Bearing in mind that our texts were incredibly short, and in our second comparison that the reference text was smaller than the rigid excerpts, we treated this analysis only as an exploratory process to highlight potential terms to further explore in the data, rather than to draw any definitive conclusions. We also explored frequencies of $n$-grams to examine instances where keywords were used within word bundles.

\section{Findings and analysis}

Table 2 displays the findings according to the 27 research areas, showing results for the top 10 journals in each subject area. While our aim is not to quantify our qualitative data, we see this as a useful starting point from which to explore the data, as it highlights potential differences in the guidelines according to journal disciplines.

Table 2 Categories of journals' language guidelines by discipline area

\begin{tabular}{llllll}
\hline & flexible & rigid & both & neutral & $\begin{array}{l}\text { not } \\
\text { mentioned }\end{array}$ \\
\hline Agriculture & $2^{*}$ & 4 & 0 & $4^{*}$ & 0 \\
\hline Arts \& Hum & 1 & 0 & 0 & $7^{*}$ & $2^{*}$ \\
\hline Biochem & 0 & 0 & $1^{*}$ & 2 & $7^{*}$ \\
\hline Business & 2 & $3^{*}$ & 0 & 0 & $5^{*}$ \\
\hline Chem Eng & $2^{*}$ & $4^{*}$ & $1^{*}$ & 1 & $2^{*}$ \\
\hline Chemistry & $2^{*}$ & $8^{*}$ & 0 & 0 & 0 \\
\hline Comp Sci & $2^{*}$ & $3^{*}$ & 0 & $3^{*}$ & $2^{*}$ \\
\hline Decision Sci & 0 & $3^{*}$ & $1^{*}$ & $3^{*}$ & $3^{*}$ \\
\hline Dentistry & 0 & 8 & 0 & 1 & 1 \\
\hline Earth Sci & 1 & 4 & 1 & $2^{*}$ & 2 \\
\hline Economics & 0 & $3^{*}$ & 0 & 1 & $6^{*}$ \\
\hline Energy & 0 & $6^{*}$ & $1^{*}$ & 2 & $1^{*}$ \\
\hline Engineering & 0 & $7^{*}$ & $1^{*}$ & $1^{*}$ & $1^{*}$ \\
\hline Environ Sci & 0 & 5 & $2^{*}$ & $2^{*}$ & $1^{*}$ \\
\hline Health & 0 & 6 & 0 & 1 & $3^{*}$ \\
\hline Immunology & $1^{*}$ & 4 & 0 & $2^{*}$ & $3^{*}$ \\
\hline Materials Sci & 0 & $6^{*}$ & $2^{*}$ & $2^{*}$ & 0 \\
\hline
\end{tabular}




\begin{tabular}{llllll}
\hline Mathematics & $1^{*}$ & 2 & $1^{*}$ & $3^{*}$ & $3^{*}$ \\
\hline Medicine & 0 & 1 & $1^{*}$ & $2^{*}$ & $6^{*}$ \\
\hline Multidiscipl & 1 & 4 & 0 & $2^{*}$ & 3 \\
\hline Neuroscience & 1 & $5^{*}$ & 3 & 0 & 1 \\
\hline Nursing & 0 & 5 & 1 & 2 & 2 \\
\hline Pharmacology & 0 & $5^{*}$ & 2 & 2 & 1 \\
\hline Physics & 1 & $4^{*}$ & $3^{*}$ & $2^{*}$ & 0 \\
\hline Psychology & 1 & $2^{*}$ & 0 & $5^{*}$ & 2 \\
\hline Social Sci & 0 & 1 & $1^{*}$ & $2^{*}$ & $6^{*}$ \\
\hline Veterinary & 0 & 7 & 0 & 2 & 1 \\
\hline TOTAL & 18 & 110 & 22 & 56 & 64
\end{tabular}

Note. 60 of the 270 journals are listed in multiple categories (e.g. arts/humanities and psychology, biochemistry and medicine, business and economics), so those numbers are marked with an asterisk

\subsection{Consideration of conceptions of language errors, standards, norms, and nativeness}

Notable here is how few journals promote flexible guidelines for contributing authors, explicitly pointing to non-standard forms of the English language. In more than half of the subject areas, none of the top 10 journals provided such guidelines. However, it is also notable that journals in Arts and Humanities (including language and linguistics journals) and Biochemistry had no rigid guidelines, and Medicine and Social Sciences had just one rigid guideline each.

The few flexible journals made general, open statements about using language appropriate for an international readership. The guidelines focused on the importance of "clear and concise language" that could be understood by "broad readership", without a need to adhere to "native" benchmarked norms. For example, the Bioinformatics (Computer science) author guidelines stated:

Language editing, if your first language is not English, to ensure that the academic content of your paper is fully understood by journal editors and reviewers is optional. [emphasis added].

While this language guideline is somewhat awkwardly stated, it nevertheless sends an explicit message of openness to potential authors regarding flexibility of language use. It therefore serves as a valuable example of the journal's prioritization of content over adherence to native-benchmarked language standards.

In other flexible guidelines, English L2 authors were not specifically targeted, but guidelines indicated a need to write to a broad international audience. For example, the guideline for Angewandte Chemie - International Edition (Chemical engineering) stipulated: "Authors are asked to make their manuscripts suitable for a heterogeneous readership-please use a clear style and avoid jargon". The guidelines for Scientific Reports acknowledged diverse readership, and specifically addressed L2 English speakers as part of this readership: 
Scientific Reports is read by scientists from diverse backgrounds. In addition, many are not native English speakers. Authors should, therefore, give careful thought to how their findings may be communicated clearly.

It is significant to note here that this journal implicitly suggested a need for all writers to adapt to L2 English readers, and not vice versa-a statement which seems to be highly sensitive to the global use of language in ERPP. These were the only few examples where the guidelines explicitly indicated that $L 2$ English readership was important to the journal, and thus language needed to be adapted for communication to a wide audience. The subtext here is that L1 English writers might also need to edit and adapt their language, so the power relationship is disrupted from traditional viewpoints of L1 users as norm-providing.

Other journal guidelines were less obviously categorized as flexible, and their placement required interpretations from all researchers. They were seen as flexible due to intentional avoidance of norms or "native English", such as Astrophysical Journal: "Authors whose grasp of written English is not secure should obtain help from colleagues proficient in English". Important to note here is how this guideline avoids the pitfalls of the native check, that is having a "native speaker" of English check the manuscript before submission. While it does not explicitly suggest that the journal accepts flexible forms of the language, it does implicitly invite less proficient writers to submit to the journal with the help of capable others, who are not labelled explicitly as "native" speakers of English. We felt that the careful wording of this guideline was intentionally produced to avoid native benchmarks.

Several of the neutral guidelines were found to address the importance of clarity for the purposes of readership, but with somewhat muddled messages surrounding the notion of errors. The guideline of Econometrica is an illustrative example:

Write crisply but clearly. Avoiding grammatical and notational errors, though important, is only the first step. Good writing, especially good mathematical writing, calls for something more: the extra effort involved in revising and reworking the manuscript until it will be clear to most if not all of our readers. The neutrality found in the wording of such guidelines is differentiated from others identified as being both rigid and flexible. Neutral guidelines were found to mention avoidance of errors in the effort of maintaining clarity. Guidelines placed in the 'both' category, alternatively, did not make the same connection, instead referring to a flexible position in one part, and to a rigid position in another. For example, the Nature journal guidelines stipulate:

No paper will be rejected for poor language. However, if you would like assistance with writing your manuscript, you can consider asking a colleague whose native language is English for their input... [emphasis added] 
The statement that poor language may be acceptable is clearly flexible; however, the suggestion that a native English-speaking colleague would be able to assist in the use of language indicates a rigid position.

Rigid guidelines were found to position English L2 authors from a deficit perspective (rather than the difference perspective described in the ELF literature), suggesting they need assistance to reach a native-like standard. This was typically couched in associated advertisements for editing services linked to the journal. The language guidelines from the journal Neuropsychopharmacology serve as a typical illustration:

Improve your written English: sound like a native English speaker with editing from our experts. We can improve the language in all of your research-related documents: for example, research papers, grant applications, books, theses, reports, and news articles. [emphasis added]

Other statements in the journal guidelines were more clearly rigid, such as that of Reviews of Modern Physics: "If your native language is not English, please consider enlisting the help of an English-speaking colleague in preparing the text." Here the journal explicitly separates non-native English writers from other "English-speaking" writers, indicating that only L2 English writers are advised to seek help in their writing.

Many of the statements which were used to categorize journal guidelines as rigid were found in texts associated with professional editing services. These varied according to the journal publisher with Elsevier's WebShop (35 journals) and Wiley's services (26) advertised most often, followed by Springer (10), Oxford Editing (5), Nature Research Editing Service (5), and Sage (4). Sage editing service's description reflected a very traditionalist, non-flexible perspective, and explicitly focused on error:

Standard Editing focuses on correcting spelling, grammar, and punctuation errors. Our Editors will change improper language and suggest alternate phrasing when poor wording is used. The Editors will alter sentences that sound awkward or unnatural and may point out portions of the manuscript that are vague or confusing or simply need to be rewritten.

Here, there is emphasis on eliminating "improper" or "unnatural" language to produce error-free writing. However, there is no explicit correlation of error and L2 writing. That is, while the editing service takes a rigid position on error, it does not target its service to L2 writers only.

Many editing services directly targeted L2 English authors for their editing service. Illustrative of this was the journal Nature Immunology, which stated: "Improve your written English: sound like a native English speaker with editing from our experts". Notable in both Sage editing service's and Elsevier WebShop's descriptions are the use of particular key terms, such as correct(ing), error, improper, poor wording, unnatural, and accurate(ly). These terms and others within the guidelines were significant in our interpretations and are explored further in the following section. 


\subsection{An analysis of emergent key terms}

To analyze key terms, AntConc (Anthony, 2018) was used to first analyse the rigid guidelines against a reference text made up of flexible and neutral guidelines. Then flexible guidelines were analysed against a reference text of rigid and neutral guidelines. Words that stood out as meaningful (i.e. not grammatical or functional), appeared three times or more and had a keyness (log likelihood) above $6.63(p<.01)$ were qualitatively explored to investigate differences in use.

\subsubsection{Key terms signaling errors, standards, norms, and nativeness}

Upon review of the long list of potential keyword items, some terms were significant only because they were repeated in standardized statements used by journal publishers across numerous journals (e.g. require, conform, and eliminate). Controlling for these words as well as functional and grammatical items, the remaining words are listed in Table 3.

Table 3 Key terms used in rigid guidelines

\begin{tabular}{|l|l|l|}
\hline Key term & $\begin{array}{l}\text { Number of guidelines } \\
\text { word appears }\end{array}$ & Keyness \\
\hline Correct & 34 & LL 14.61 $(\mathrm{p}<0.001)$ \\
\hline Speaker & 19 & LL 11.75 $(\mathrm{p}<0.001)$ \\
\hline Grammatical & 28 & LL 11.27 $(\mathrm{p}<0.001)$ \\
\hline Native & 37 & LL $9.53(\mathrm{p}<0.01)$ \\
\hline Error & 30 & LL $8.89(\mathrm{p}<0.01)$ \\
\hline Edited & 18 & LL 11.13 $(\mathrm{p}<0.001)$ \\
\hline Improve & 27 & LL $7.44(\mathrm{p}<0.01)$ \\
\hline
\end{tabular}

The key term correct appeared in 34 language guidelines and qualitative analysis of the term in its original contexts confirmed all 34 uses as rigid. Correctness was often discussed in a similar space as grammar, such as the word bundle grammatically correct. A Key Word in Context (KWIC) index, a common format for concordance lines, revealed that correct was almost always used to refer to a language standard (Figure 1). Upon further examination of neighboring text (not shown in Figure 1), in many cases the correct English that manuscripts were required to conform to was explicitly identified as American or British English, such as: "Please write your text in good English (American or British English is accepted, but not a mixture of these)".

\begin{tabular}{|rl} 
pts should be written in concise and & correct English, and at a level that will \\
be written in clear, concise and grammatically & correct English. Authors for whom English is their \\
be concisely and clearly written in grammatically & correct English. Manuscripts must be written in English \\
Manuscripts must be submitted in grammatically & correct English. Manuscripts that do not meet this \\
or spelling errors and to conform to & correct scientific English may wish to use the \\
need support to write your paper in & correct scientific English, you may wish to make \\
are trouble spots and you cannot yourselves & correct these, then you would be well advised
\end{tabular}

Figure 1: KWIC examples of use of correct 
The key term error was used alongside many other key terms like edited which were associated with avoidance of poor language via use of proper English, such as in the guidelines for the journal Biological Psychiatry:

Between 30 percent and 50 percent of articles submitted to Elsevier journals are rejected before they even reach the peer-review stage, and one of the top reasons for rejection is poor language. A properly written, edited and presented text will be error free and understandable and will project a professional image that will help ensure your work is taken seriously in the world of publishing. [emphasis added]

The message here is explicit: that language is one of the top criteria for initial editor rejection, rather than a study's contribution to knowledge. It is clearly a contentious issue and one which supports literature that suggests a disadvantage for $L 2$ writers in the academic publishing process (e.g. Lilis \& Curry, 2018).

Except for one flexible journal guideline (Scientific Reports), which noted that "many [readers] are not native English speakers", the terms native and speaker were associated with rigid guidelines. Investigation of the n-grams in the text revealed the terms were often used within the word bundles native speaker or native English speaker. Typically, these examples emphasized the importance of a native check of the manuscript. Many of the journals published by Elsevier stated that if L2 English authors need help with their writing, they should consider "asking a colleague who is a native English speaker to review your manuscript for clarity" [emphasis added]. Journals with other publishers made similar suggestions. ACS Nano (ACS Publications) stated that "any author who is not fully fluent in idiomatic English is urged to obtain assistance with manuscript preparation from a colleague whose native language is English" [emphasis added]. The British Journal of Sports Medicine (BMJ Publishing Group) stated, "If you're not a native English speaker, we recommend you get your manuscript edited by native speakers before submitting" [emphasis added].

\subsubsection{Key terms associated with flexibility}

A comparison of flexible guidelines against the reference corpus of rigid and neutral texts revealed a much shorter list of potentially significant items. Note that neutral and rigid guidelines were included in the reference corpus to ensure it was substantially larger than the comparison text, and contained a range of statements against which to compare the flexible guidelines. The keywords are shown in Table 4.

Table 4: Key terms used in flexible guidelines

\begin{tabular}{|l|l|l|}
\hline Item & Frequency & Keyness \\
\hline Colleagues & 14 & $\mathrm{LL}=16.69(\mathrm{p}<0.0001)$ \\
\hline Concise & 4 & $\mathrm{LL}=12.42(\mathrm{p}<0.001)$ \\
\hline Readership & 3 & $\mathrm{LL}=11.8(\mathrm{p}<0.001)$ \\
\hline Clear & 6 & $\mathrm{LL}=8.8(\mathrm{p}<0.01)$ \\
\hline Style & 3 & $\mathrm{LL}=7.16(\mathrm{p}<0.01)$ \\
\hline
\end{tabular}


Key terms clear and concise, as well as readership were often used within a similar space to discuss the need to write with clarity for a broad readership. This often pointed toward a flexible guideline, such as Molecular Systems Biology, which happened to include all three of these words:

Manuscripts must be written in clear and concise English and be intelligible to a broad readership. [emphasis added]

The term style, was also used in similar space as readership, such as the following guideline: "Authors are asked to make their manuscripts suitable for a heterogeneous readership - please use a clear style and avoid jargon" [emphasis added]. Style was also used in place of benchmarks, such as requesting authors improve "the standard and style of their writing" or adhere to the "journal style". This raises implications discussed in the next section.

When the word colleague was further investigated, it became apparent that the term served as a replacement to the term native English speaker found in the rigid guidelines. Two different journals suggested that "prior to submission, authors may benefit from having their manuscript reviewed for clarity by colleagues". Another journal identified suitable colleagues as being "proficient in English", thus removing the quality of nativeness. A further journal suggested that such checks extended beyond language, suggesting that authors "circulate your manuscript among colleagues before submitting to SMJ, and make revisions based on their thoughtful suggestions". Such guidelines sent a clear message that all writers (no distinction between L1 and L2 users) would benefit from the help of colleagues (again, no distinction made between L1 and L2 English speakers).

\section{Discussion}

The study has highlighted how concepts of error are presented to authors writing in ERPP. Research question one investigated the conceptions of language errors, standards, norms, and nativeness in journal language guidelines for authors. Many statements specifically promoted the need for writing "free from grammatical errors", with some journals indicating that error-free writing was one of the main editorial criteria required for the manuscript to be considered for peer review.

Many of the journal guidelines in our dataset discussed L2 writing and error within the same space. The data show that norms, when presented, were usually benchmarked against "scientific English", or more elusively against a native-speaker yardstick, which was not clearly defined. Statements about error, correctness, and use of proper English were usually couched within advertisements of editorial services, mostly (but not always) aimed at the L2 English writer. Further statements, such as those suggesting L2 writers should have their language checked "by a native speaker", positioned native speakers as authorities on error-free writing.

Most guidelines could be seen to adopt the traditional approach to error, viewing "L2 writers' texts as distinct from L1s" (Heng Hartse \& Kubota, 2014, p. 73). Many of the 
rigid guidelines either explicitly or implicitly elevated the notion that there was one (or sometimes two in the case of British and American) standard English, and this standard was required by the journal. No guideline explicitly adopted a World Englishes or translingual approach to error as argued by Heng Hartse and Kubota (2014), even though some flexible guidelines implicitly communicated an openness to deviations from standards, so long as the content was clear.

Regarding research question two, our analysis has helped to highlight key terms used to communicate flexibility in author guidelines. It shows that flexible guidelines highlight the global readership of journals, and a need for authors to communicate ideas clearly to this diverse audience. It acknowledges that good writing can emerge from both L1 and L2 writers. As such, experienced L1 and L2 colleagues are in an important position to offer help to less confident writers (both L1 and L2 alike) who may struggle with the conventions of ERPP. Such results indicate how guidelines can be worded to be more inclusive of different forms of English. Our keyword analysis shows that journals can discuss language requirements in terms of clarity and conciseness, rather than in terms of correctness and error. Benchmarks in flexible guidelines can refer to a need to adhere to specific publishing styles, rather than abstract native forms. Further to this, flexible guidelines clearly discussed language within the context of a broad readership of the journal, which included a need for manuscripts to be understandable to both L1 and $L 2$ readers.

In contrast, the study also highlights problematic wording in rigid guidelines, which need to change if a journal is to become more open to diverse usage of English. Rigid guidelines polarize native and non-native speakers, conflating native speakers as authorities of the language by encouraging native checks and targeting editing services only to L2 writers. Rigid guidelines highlight a need for error-free writing; they elevate native norms as the only acceptable standard, and position language as a major criterion for article rejection.

\subsection{Transferability of findings}

Curry and Lillis (2018) argue that claims surrounding publishing in English are "usually supported by evidence from the limited universe of around 27,000 journals included in the Web of Science (WoS) indexes", but the publishing world is much bigger. As our sample looked only at top indexed journals, this may point to a potential lack of representativeness of our findings. To evaluate the transferability of our findings against previous research, we discuss them within a wider literature on author guidelines.

In other literature, some journals appear to have taken the lead in their author guidelines to allow for more flexibility. For example, Galloway and Rose (2015) draw our attention to two science journals published by Cambridge University press, the Journal of Cardiology of the Young, and Seed Science Research, which state:

The language of the Journal is English, but acceptance of a manuscript will reflect scientific rather than grammatical content. The editors undertake to 
facilitate the publication of papers from those authors whose native language is not English.

Such findings resonate with our own examples of flexible guidelines, such as Bioinformatics (Computer science) which suggested that language editing, for L2 writers was 'optional'.

A more daring example referred to in numerous studies (e.g. Clouet, 2017; Heng Hartse \& Kubota, 2014) is the Journal of English as a Lingua Franca (JELF), where editors explicitly challenge publisher guidelines. The editors explicitly state their noncompliance with the guidelines of the journal publisher (De Gruyter Mouton):

Authors should follow the De Gruyter Mouton style sheet but with one change: While the standard style sheet stipulates, under 'Special attention', that authors should have their "contribution carefully checked by a native speaker", the editors of JELF simply expect authors to submit manuscripts written in an English which is intelligible to a wide international academic audience, but it need not conform to native English norms.

While these examples are very few in the massive list of academic publications, they are significant in their efforts to break away from traditional ideologies of standards in publishing. Galloway and Rose (2015) state that these movements indicate a future in which academic English is no longer under the control of academic publishers, as they aim "to be more inclusive of research that might previously have been dismissed on language grounds alone" (p. 235). However, our data suggest this future may still be a long way off, with most journals in our sample purporting rigid ideologies.

In its simplest terms, ERPP is clearly torn between two mediating forces: a need for linguistic clarity in journal publications so that research can be understood with unambiguity; and a need to be inclusive of a global academic community, many of whom are L2 writers. Much of the problem emanating from this context is due to an ideology that linguistic clarity is achieved through error-free writing, as benchmarked by 'native-speaker' standards.

\section{Limitations, implications and conclusion}

While an analysis of 210 journals' language guidelines was a good start for a study such as this, there is a need to explore further guidelines in each of the topic areas for better cross analysis. Further, as this study explored the "limited universe" (Curry \& Lillis, 2018, p. 1) of indexed journals, there is scope to compare these findings to newer, emerging, or non-indexed journals which may be more independent from traditional publisher demands and reader expectations. In addition, due to the discovery that for some disciplines their guidelines were drawn along publisher lines rather than research discipline lines (as evidenced by the repeated guidelines of Elsevier, Wiley, Springer, and so on), a further study could explore such distinctions and potentially reveal important insights. Such a study should also take into consideration the guidelines of 
editing services associated with the publishers, as these were the source of so many of the rigid guidelines identified in the study. It could be that some of these messages (such as those indicating poor language will lead to article rejection) are not held up in practice by the editors and reviewers themselves, as has been suggested by Hyland (2016).

Following trends of internationalization in higher education, we can predict that the numbers of L2 English users engaging in academic English will continue to rise. Some academic publications are responding to the variations of language being produced by writers from around the globe with a relaxation of language-related requirements placed on their authors. However, Curry and Lillis (2018) suggest that journal editors and referees need to have more tolerance for non-standard Englishes when reviewing texts, and that journal publishers need to develop to better ways to support multilingual writers. The selling of editing services, which comes at a huge cost to L2 writers, without any guarantee to acceptance in the journal, is clearly not a positive way forward.

The call for a redefinition and re-conceptualization of error has been around for decades, and the recent developments in emerging fields of written ELF and ERPP in global contexts indicate there is academic support for change. It is time that we universally adopted a more open and flexible orientation to language in ERPP and clarified that error-free writing need not be an insurmountable barrier to L2 writers (or any writer for that matter). It is important that journal guidelines communicate this appropriately to potential authors so that the contribution to knowledge of their papers is the primary criterion of evaluation. It is time that the publishing world of academia became open to a more nuanced and global view of the English language.

\section{References}

Anthony, L. (2018). AntConc (Version 3.5.7) [Computer Software]. Tokyo, Japan: Waseda University. Available from http://www.laurenceanthony.net

Bergsma, S., Post, M., \& Yarowsky, D. (2012). Stylometric analysis of scientific articles. In Proceedings of the 2012 Conference of the North American Chapter of the Association for Computational Linguistics: Human Language Technologies (pp. 327-337). Association for Computational Linguistics.

Canagarajah, S. (2015). Clarifying the relationship between translingual practice and L2 writing: addressing learner identities. Applied Linguistics Review, 6(4), 415-440. Doi:10.1515/applirev-2015-0020

Cargill, M., \& Burgess, S. (2008). Introduction to the special issue: English for research publication purposes. Journal of English for Academic Purposes, 7(2), 75-76. Doi:10.1016/j.jeap.2008.02.006 
Clouet, R. (2017). The intercultural dimension of English as an Academic Lingua Franca (EALF) in scientific publications. Revista de Lenguas para Fines Específicos, 23(2), 313-333.

Curry, M. J. \& Lillis, T. (2018). The Dangers of English as Lingua Franca of Journals. Inside Higher Ed. Retrieved March 13 at https://www.insidehighered.com/views/2018/03/13/domination-englishlanguage-journal-publishing-hurting-scholarship-many-countries

Duszak, A., \& Lewkowicz, J. (2008). Publishing academic texts in English: A Polish perspective. Journal of English for Academic Purposes, 7, 108-120. Doi:10.1016/j.jeap.2008.03.001

Ferguson, G., Perez-Llantada, C., \& Plo, R. (2011). English as an international language of scientific publication: A study of attitudes. World Englishes, 30(1), 41-59. Doi:10.1111/j.1467-971X.2010.01656.x

Galloway, N. \& Rose, H. (2015). Introducing Global Englishes. Abingdon: Routledge.

Gamon, M. (2010). Using mostly native data to correct errors in learners' writing: a meta-classifier approach. Proc. HLT-NAACL, pp. 163-171.

Gentil, G., \& Séror, J. (2014). Canada has two official languages-Or does it? Case studies of Canadian scholars' language choices and practices in disseminating knowledge. Journal of English for Academic Purposes, 13, 17-30.

Doi:10.1016/j.jeap.2013.10.005

Han, N.-R., Chodorow, M., \& Leacock, C. (2006). Detecting errors in English article usage by non-native speakers. Natural Language Engineering, 12(2), 115-129. Doi:10.1017/S1351324906004190

Hanauer, D. I., \& Englander, K. (2011). Quantifying the burden of writing research articles in a second language: Data from Mexican scientists. Written Communication, 28, 403-416. Doi:10.1177/0741088311420056

Harris, M. (1981). Mending the Fragmented Free Modifier. College Composition and Communication, 32(2), 175-182. Doi:10.2307/356691

Hartwell, P. (1985). Grammar, grammars, and the teaching of grammar. College English, 47(2), 105-127. Doi:10.2307/376562

Hartse, J. H., \& Kubota, R. (2014). Pluralizing English? Variation in high-stakes academic texts and challenges of copyediting. Journal of Second Language Writing, 24, 71-82. Doi:10.1016/j.jslw.2014.04.001 
Huang, F. (2015). Building the world-class research universities: a case study of China. Higher Education, 70(2), 203-215. Doi:10.1007/s10734-015-9876-8

Hwang, K. (2005). The inferior science and the dominant use of English in knowledge production: A case study of Korean science and technology. Science Communication, 26, 390-427. Doi:10.1177/1075547005275428

Hyland K. (2016). Academic publishing and the myth of linguistic injustice. Journal of Second Language Writing, 31, 58-69. Doi:10.1016/j.jslw.2016.01.005

Ingvarsdóttir, H., \& Arnbjörnsdóttir, B. (2013). ELF and academic writing: A perspective from the expanding circle. Journal of English as a Lingua Franca, 2(1), 123-145. Doi:10.1515/jelf-2013-0006

Jenkins, J. (2000). The Phonology of English as an International Language. Oxford: Oxford University Press.

Jenkins, J. (2006). Points of view and blind spots: ELF and SLA. International Journal of Applied Linguistics, 16(2), 137-162. Doi:10.1111/j.1473-4192.2006.00111.x

Jenkins, J. (2009). English as a lingua franca: Interpretations and attitudes. World Englishes, 28(2), 200-207. Doi:10.1111/j.1473-4192.2006.00111.x

Jenkins, J. (2011). Accommodating (to) ELF in the international university. Journal of Pragmatics, 43(4), 926-36. Doi:10.1016/j.pragma.2010.05.011

Kubota, R. (2015). "The multi/plural turn and implications for second language writing", Paper presented at the Symposium on Second Language Writing, Auckland, New Zealand.

Kuckartz, U. (2014). Qualitative text analysis: a guide to methods, practice \& using software. London: Sage.

$\mathrm{Li}, \mathrm{Y}$. (2014). Seeking entry to the North American market: Chinese management academics publishing internationally. Journal of English for Academic Purposes, 13, 41-52. Doi:10.1016/j.jeap.2013.10.006

Lillis, T. M. \& Curry, M. J. (2010). Academic writing in a global context: The politics and practices of publishing in English. London: Routledge.

Martinez, R. (2018). "Specially in the last years...": Evidence of ELF and non-native English forms in international journals. Journal of English for Academic Purposes, 33, 40-52. Doi:10.1016/j.jeap.2018.01.007

Mauranen, A. (2012). Exploring ELF: Academic English shaped by non-native speakers. Cambridge University Press. 
Mauranen, A. (2016). Changing language in changing global academia. In Murata, K. (Ed.) Exploring ELF in Japanese Academic and Business Contexts:

Conceptualisation, research and pedagogic implications, 29-46. Abingdon:

Routledge.

May, S. (2014). Introducing the "Multilingual Turn." In S. May (Ed.), The Multilingual Turn. Implications for SLA, TESOL and Bilingual Education. (pp. 1-6). New York, NJ: Routledge.

McGrath, L. (2014). Parallel language use in academic and outreach publication: A case study of policy and practice. Journal of English for Academic Purposes, 13, 516. Doi:10.1016/j.jeap.2013.10.008

Montgomery, S. L. (2013). Does science need a global language?: English and the future of research. Chicago: University of Chicago Press.

Olsson, A., \& Sheridan, V. (2012). A case study of Swedish scholars' experiences with and perceptions of the use of English in academic publishing. Written Communication, 29(1), 33-54. Doi:10.1177/0741088311428566

Ortega, L. (2013). SLA for the 21st Century: Disciplinary Progress, Transdisciplinary Relevance, and the Bi/multilingual Turn. Language Learning, 63(1), 1-24. Doi:10.1111/j.1467-9922.2012.00735.x

Politzer-Ahles, S., Holliday, J. J., Girolamo, T., Spychalska, M., \& Berkson, K. H. (2016). Is linguistic injustice a myth? A response to Hyland (2016). Journal of Second Language Writing, 34, 3-8. Doi:10.1016/j.jslw.2016.09.003

Rose, H. \& McKinley, J. (2018). Japan's English medium instruction initiatives and the globalization of higher education. Higher Education, 75(1), 111-129.

Seidlhofer, B. (2011). Understanding English as a Lingua Franca. Oxford: Oxford University Press.

Shaughnessy, M.P. (1979). Errors and expectations: A guide for the teacher of basic writing. Oxford University Press.

Wallwork, A. (2016). Academic Written English: What it is and how to teach it. Springer.

Weisman, D., \& Zornado, J. L. (2017). Professional writing for social work practice. Springer. 